\title{
Children's relationships with birth parents in childhood and adulthood: A qualitative longitudinal study of kinship care
}

\author{
Jeanette Skoglund, Renee Thørnblad, Amy Holtan
}

\begin{abstract}
The topic of interest in this paper is the relationship between children who live in kinship care and their birth parents - through childhood and adulthood. The focus is on what meaning and content children themselves ascribe to such relationships and how this changes over time. To explore this question, we draw on a qualitative longitudinal data set, in which children who grew up in kinship foster care in Norway were interviewed over a 15-year period. We have selected three cases, where we follow two girls and one boy through their three interviews as children (T1: 11-12 years old), emerging adults (T2: 20-21 years old) and young adults (T3: 28-29 years old). Through the adoption of a methodological approach with similarities to biographical approaches, our analysis gives unique insight into the interviewees' relationships with their birth parents - how they are expressed in each interview as their lives unfold and as circumstances change. More specifically, the analysis gives insight into different types of parent-child relationships and how they may change over time. However, it also shows that the interviewees have different resources available in managing such relationships. This is an issue rarely recognised in child welfare research or practice, yet it is essential if we want to understand the relationship between children who grow/grew up in foster care arrangements and their birth parents.
\end{abstract}

Keywords: Qualitative longitudinal research, kinship foster care, birth parent-child relationship, case study 


\section{Introduction}

The topic of interest in this paper is the relationship between children who live in long-term kinship care1 and their birth parents - through childhood and adulthood. According to the United Nations Convention on the Rights of the Child (UNCRC), Article 9 (United Nations General Assembly, 1989), children who are separated from their birth parents have the right to 'maintain personal relations and direct contact with both parents on a regular basis, except if it is contrary to the child's best interests'. In line with the UNCRC, legislation in Norway and in other countries places a duty on child protective services (CPS) to facilitate contact between children and their birth parents.2 Prior to the 1970s, such contact was given little consideration. At times it was even discouraged (Bullen et al., 2015; Haugli and Havik, 2010). Changing conceptions of contact derive from an understanding that children and their birth parents belong together, in Norway known as the 'biological principle' (Haugli and Havik, 2010). The primary aim of birth parental contact is to maintain and support the relationship between children and their birth parents, an aim generally grounded in theories of attachment (Bowlby, 1969; Sen and Broadhurst, 2011). From this perspective, parental relationships are seen as important for children's emotional and psychological well-being, and for meeting their developmental needs (Neil and Howe, 2004). Moreover, it has been argued that contact allows children and young people to have a more realistic view of their birth parents (Fahlberg, 1991), and to preserve their family relationships (Mallon and Hess, 2014). In Norway, the importance given to biological relations co-exists with a 'child-focussed' orientation, informed primarily by psychological knowledge. For example, a recent governmental report recommended that the biological principle should be subordinated to a new principle called 'attachment-supportive development'. Here, it was suggested that the rights of children and birth parents to have contact should be maintained only to the extent that they allow the development of a bond of attachment which supports the child's development (Raundalen, 2012). While birth parental contact is an issue of some prominence in the kinship and non-kinship care literature (Kiraly and Humphreys, 2013a; Milham et al., 1986; Sen and Broadhurst, 2011), the relationship between children who grow up in longterm foster care and their birth parents has gained little attention. As opposed to the few studies which do explore such relationships (e.g. Maaskant et al., 2016), this study is not embedded in the psychological tradition, but uses theories from sociology.

In this paper we ask: What content and meaning do children themselves ascribe to such relationships and how does this change over time? To explore this question, we draw on a qualitative longitudinal data set in which children who grew up in kinship care in Norway were 
interviewed over a 15-year period. We have selected three case studies where we follow two girls and one boy through their three interviews as children (T1: 10-11 years old), emerging adults (T2: 19-20 years old) and young adults (T3: 28-29 years old).

A recent literature review on family contact in kinship care (Kiraly and Humphreys, 2013a) shows that most studies on this issue have focused on children's contact with their birth parents. Other relationships, such as those with siblings have gained less attention. To avoid romanticising the relationship between children and their birth parents, we have adopted a methodological approach with similarities to biographical approaches where we more or less 'walk alongside' (Neale et al., 2012) the three interviewees through their changing lives and family circumstances, from childhood to adulthood. By walking alongside Jonas, Maja and Ann we explore how their relationships with their birth parents are expressed in each interview as their lives unfold. This, we argue, allows us to construct images closer to the ones which the interviewees themselves seek to portray.

\section{Theoretical background}

In the out-of-home care literature, parental contact refers most commonly to intentional communication between children and their birth parents. Contact can be direct (e.g. face-toface meetings) or indirect (e.g. via phone calls), supervised (e.g. by social workers) or unsupervised (Sen and Broadhurst, 2011). Children are more likely to have contact with their birth mothers than with their birth fathers, especially when they live with maternal relatives (Aldgate and McIntosh, 2006; Farmer and Moyers, 2008). Some studies have registered more contact occurring in kinship care and with more informality compared to other foster care arrangements (Taplin and Mattic, 2011). This means that many children who grow up with relatives in foster care also see their birth parents outside the contact agreement made by CPS. However, some children only see their birth parents on rare occasions, and grow up in families with similarities to families of adoption.

While birth parental contact is fairly easy to define, family relationships and the relationship between children and their birth parents are complex phenomena, and can be viewed from different perspectives. At a social and cultural level, family relationships are expected to offer support, care and love, and to entail emotional closeness. Among these relationships, the one 
between children and birth parents, especially mothers, holds a unique position in our minds; it is seen to be the strongest, most enduring relationship in our lives (Rossi and Rossi, 1990).

In the sociology of family life, the terms practices (Morgan, 1996) and negotiations (Finch and Mason, 1993) have been developed to capture the active aspects of Skoglund et al. 3 family life and relationships. They remind us that the 'reality' or 'nature' of relationships are not simply given by biology, but constituted through practice and negotiated and renegotiated over time. This sociological perspective allows us to explore the ways in which family members reflect upon, negotiate, and evaluate their personal and family relationships - 'the given and chosen, then and now, here and there' (Mallett, 2004: 80). The notion of 'given' is important here, because it encapsulates how family members do not necessarily have autonomy to choose or determine their relationships. Children who grow up in foster care have limited autonomy to determine their birth parents' presence or the degree of involvement in their lives. Nevertheless, children (and adults) engage in negotiations about what such relationships should be and entail; in other words, the meaning and content one person ascribes to the relationship with his or her birth parent can vary from that of another. While this is true for all relationships, including for children and birth parents who live together, it becomes more visible in long-term foster care arrangements. When the state takes over the care of the child and a foster care placement is formalised, the birth parent(s) (most often the birth mother) will no longer have the day-to-day care of the child. In kinship care settings, this involves a renegotiation of relationships and obligations between birth parents and relatives (Holtan, 2008). It is within the different family types emerging from such negotiations that children ascribe content and meaning to their relationships with their birth parents. Time plays an essential part in this, as both the past (memories, nostalgia) and the future (projects, hopes) are located in the present work of making sense of one's relationships (Morgan, 2011). Smart (2007) captures the aspect of time through her overlapping concepts of memory, biography, embeddedness, relationality and imaginary. She reminds us that when people reflect upon questions such as 'What does your mother mean to you?', this is not answered in isolation, but in relation to the wider aspects of their lives. Important here are social and cultural conceptions of motherhood and fatherhood. During the past few decades, such conceptions have changed radically in Western countries (Lee et al., 2014). Over the last half century, mothers have been increasingly urged to strive for intimacy and closeness in their relationships with their children through the investment of time, resources and emotion. This ideology has been termed intensive mothering (Hays, 1996), and has gained ground and expanded the definition of motherhood. With increased involvement and 
expectations towards fathers in childrearing, the ideal of intensity is increasingly demanded also of them (Faircloth, 2014).

Commenting on family life more broadly, Gillis (1996) has made a distinction between the families we live with (day-to-day reality) and the families we live by (idealised version). This distinction is relevant here. Most children who grow up in long-term foster care settings experience a wide gap between the ideal of what a parent should be and the reality of their birth parents' involvement in their lives. Messing's (2006) qualitative study of children growing up in kinship care reflects this gap. Of the 40 children who were interviewed through seven focus groups, most had contact with their mothers, while the birth fathers were mostly absent in the children's lives. A common topic was disappointment towards their birth parents regarding the quality of contact and the nature of their relationships with their birth mothers. Those who had both birth parents in their lives gave indications of higher expectations towards their birth mothers than their fathers; feelings of anger were often brought into the discussions. While similar findings about disappointment have been found elsewhere (Kiraly and Humphreys, 2013b), it is important to bear in mind that many children who grow up in foster care arrangements might share more positive accounts about their birth parents. However, based on both Messing and other related studies, it is clear that many children who grow up in foster care experience difficulties in relating to their birth parents. Yet, growing up with different degrees of challenging or difficult family relationships in childhood is not restricted to children who grow up in foster care. Many children in all layers of society live with difficult family relationships; they are simply less visible.

While children cannot escape family relationships, there is an idea that adults can. As emphasised by Smart (2007), such ideas have to a large degree arrived from the individualisation thesis (e.g. Beck and Beck-Gernsheim, 1995; Giddens, 1992). Yet, 'Where lives have become interwoven and embedded (on material, emotional and metaphorical levels) it becomes impossible for relationships to simply end' (Smart, 2007: 45). Nevertheless, all actors exercise agency in an attempt to exert control over their lives and relationships, even when constrained to varying degrees by social structure (Giddens, 1979; Elder, 1991). However, as in social life more generally, people have varying amounts of personal and social resources available, meaning that not everybody will manage to achieve the types of relationships they themselves wish to have. This point that we simply cannot 'end', nor necessarily 'fix' difficult relationships, but have different resources in 'managing' them, is reflected in Holland and Crowley's (2013) qualitative study of looked-after young adults (17- 
25 years). Their findings revealed that birth parents continued to have a 'powerful co-presence' in their emotional world, reflected in accounts of anger and disappointment towards the actions of birth parents. Others, on the other hand, displayed empathy and understanding towards their birth parents. It can be argued that this latter group to a larger degree managed to distance themselves from difficult memories and 'toxic' relationships with birth parents, reflecting an attempt to exert control over their lives and relationships. One of the challenges of not distancing oneself in similar ways is that one in adulthood might not be able to construct a life story that brings emotional satisfaction (Eronen, 2011). While the aim of this paper is to explore the content and meaning children ascribe to their relationships with their birth parents and how this changes over time, the issue of agency is also important; that is, whether the interviewees, in adulthood, are able to construct personal narratives that allow them to understand themselves as being in control of their lives, relationships and futures.

\section{The study}

The sample is part of a longitudinal study with children, birth parents and foster parents in kinship care, conducted in Norway between 1999 and 2000 (T1); 2006 and 2008 (T2); and 2014 and 2015 (T3). The study is national and has been approved by the Regional Ethical Committee and the Norwegian Data Inspectorate. An overview of the sample can be found in Table 1. It is described in more detail elsewhere (Holtan, 2002, 2008; Thørnblad, 2011; Thørnblad and Holtan, 2011a).

Table 1:

\begin{tabular}{|c|c|c|c|c|c|c|c|c|}
\hline INFORMANTS & \multicolumn{3}{|c|}{ T1 1999/2000 } & \multicolumn{3}{|c|}{ T2 2006/2008 } & \multicolumn{2}{|c|}{ T3 2014/2015 } \\
\hline Children's age & \multicolumn{3}{|l|}{$4-13$} & \multicolumn{3}{|l|}{$13-22$} & \multicolumn{2}{|l|}{$20-29$} \\
\hline & Interview & Survey & CBCL/PSI & Interview & Survey & CBCL/ASR & Interview & Survey \\
\hline Children in foster homes & $\mathrm{X}$ & & & $\mathrm{X}$ & $\mathrm{X}$ & $\mathrm{X}$ & $\bar{X}$ & $\bar{X}$ \\
\hline Parents & $\mathrm{X}$ & & & $\mathrm{X}$ & & & & \\
\hline Foster parents & $X$ & $X$ & $\mathrm{X}$ & $X$ & $\mathrm{X}$ & $\mathrm{X}$ & & \\
\hline Responsible author & \multicolumn{3}{|c|}{ (Name anonymised) } & \multicolumn{3}{|c|}{ (Name anonymised) } & \multicolumn{2}{|c|}{$\begin{array}{c}\text { (Name } \\
\text { Anonymised) }\end{array}$} \\
\hline
\end{tabular}

The qualitative and quantitative data collected in this study have given rich insights into the subject of kinship care in Norway through a number of publications (e.g. Holtan and Eriksen, 2006; Holtan et al., 2013; Thørnblad and Holtan, 2011a, 2011b; Skoglund et al., 2018; Vis et 
al., 2016). One of our main insights from working with this study is the variability and complexity of family forms and relationships found within the category 'kinship care'. Conducting a case study that follows two girls and one boy from childhood to adulthood, and where we explore the relationships between them and their birth parents, allows us to take this experience further.

Our analysis is based primarily on qualitative interviews with 'Jonas', 'Maja' and 'Ann'. To show the context in which they make sense of their relationships with their birth parents as children, we also use information that appeared in the interviews with their birth parents and foster parents at T1. As we show in the analysis, all three have in common that they grew up in foster care arrangements with relatives, characterised by low degrees of solidarity and high degrees of conflict between foster parents and birth parents. If we use the family typologies constructed in an analysis of kinship care families (Holtan, 2008), two (Maja and Ann) of the interviewees grew up in monopolising families and one grew up in a broken family (Jonas). In monopolising families, foster parents and birth parents have different understandings of the assignment, and both parties look upon themselves as the centre of the child's life. A broken family is a result of lengthy monopolising processes and struggles between foster parents and birth parents. The birth parents cease to maintain close contact with the child, and 'give' the child away to the foster parents.

While this is one way to view the interviewees' upbringings, it is important to highlight that the three cases reflect differences in terms of where they grew up and when and why they moved into foster care with relatives. As we show below, their life situations are also radically different in adulthood. We see this as a richness in the data, enabling us to explore variation and similarities over time.

We interviewed Jonas, Maja and Ann as children, as emerging adults, and as young adults. At $\mathrm{T} 1$ and T2, recruitment was conducted through their foster parents. At T2, they had agreed to be contacted again for a potential follow-up study. Hence, we were able to contact them directly at $\mathrm{T} 3$ with information sheets and request for participation. At T1, the children were interviewed about the previous day, and about concrete events in everyday life. Family lists (Levin, 1994) and family charts (Moxnes, 1999) were used to explore whom they understood as belonging to their family. At T2 and T3, the interviewees were asked about their childhoods and adolescence, about their families, how they experienced their life situations, and future plans. Follow-up 
questions were adjusted to the issues emerging from each specific interview. The interviews lasted from 50 to 120 minutes. All interviews were tape-recorded and later fully transcribed.

One of the major challenges in qualitative longitudinal research is preserving the anonymity of the participants. This is especially challenging in case-study research where we follow individuals over time. A focus on people who grew up in kinship care in Norway adds a further challenge, because not many children grow up this way, and Norway is a small country. It has been our aim to give in-depth insights into the participants' lives and relationships without compromising promised confidentiality. Therefore, we have made several changes to ensure anonymity, including names, localities, professions and so on. All the information we were not able to change without altering content has been left out.

Qualitative longitudinal research does not represent a unitary method or methodology, but addresses numerous possibilities for the exploration of social life (Elliot et al., 2008). It was through a more or less inductive analysis that we became aware of the challenges of exploring the interviewees' relationships with their birth parents. Their accounts of their birth parents were not simply evaluations or descriptions of their relationships with them. Rather, they were constructed in relation to their life situations and current projects, their birth parents' life situations, other relationships such as those with their foster parents and so on. Acknowledging the complexity of this issue and the importance of each individual's life trajectory embedded in a web of relationships (Smart, 2007), we drew 'life lines' of each of the three interviewees based on their three interviews. These life lines consisted of factual aspects of their life situations (e.g. living arrangements and job situation) and subjective opinions of life situations (including expressed emotions). We also explored changes in family situations from T1 through to T2 and T3 (e.g. divorce, death) and added whom the interviewees included as being part of their families (and whom they didn't), and why they did so, over time. Working this way, we managed to approach wider aspects of the data, while also drawing a frame in which to analyse their relationships with their birth parents. In doing so, we worked both synchronically (comparison of data at each data collection round) and diachronically (looking at individuals through time). Similar analytical strategies have been used also in other qualitative longitudinal studies (e.g. Thomson et al., 2004). 


\section{Jonas}

Jonas was 11 years old when we interviewed him for the first time. He had lived with his aunt, Maria, in foster care since he was 2 months old. His birth mother, Anna (Maria's sister-in-law), who struggled with mental illness, had not been able to take care of him herself. Anna had wanted Maria and her brother, Maria's husband, to care for Jonas. When her brother died just a year later, Anna wanted Jonas to continue to live with Maria. Because of his death, we have not included Jonas's uncle in his story, nor his birth father, who moved abroad before Jonas was born.

The original basis for the foster care arrangement was for Maria (and originally her husband) to help Anna until her situation had improved, not a long-term placement. When Jonas was 3 years old, Anna had managed to get back on her feet and wanted her son back. However, during these 3 years Maria's understanding of the arrangement had changed. While the main intention was to help Anna, the focus was now on Jonas. She saw him as her son and herself as his parent. After lengthy periods of conflict between the two parties, Anna ceased to maintain close contact with Jonas and 'gave' him to Maria. In the interview with Anna at T1, she said that legally she could regain custody of Jonas, but wanted to do what was best for him.

When interviewed at this point, Jonas had only met Anna on rare occasions such as family events and arranged meetings through CPS. Jonas said that he knew Anna was his birth mother, but that he regarded her as 'more of an aunt or something'. He added further:

I can't say that I miss Anna - I was with her for only two months... . And I can't look at her as my mother when we were only together for two months. I have been with Maria for twelve years now.

Reflecting further upon his relationship with Anna, Jonas replaced biological criteria for motherhood with time spent together. Maria had been his parent for 12 years, and therefore she was his mother. In doing so, he implicitly constructed a hierarchy where Maria was ranked as closer to him than Anna, while simultaneously displaying which of the two relationships had the character of a parent- child relationship.

In the years following the first interview, greater changes occurred which impacted on Jonas's life and living situation. Maria's drinking habits developed into a severe alcohol problem, and when Jonas was 14 years old, he called his caseworker and told her that he could not live with 
Maria any longer. In the following period, it was decided that Jonas was going to live with a new foster family.

This meant that when we interviewed Jonas for the second time, he had experienced what CPS would define as neglect for the second time in his life. He was 20 years old at this point, and still lived with his 'new' foster parents whom he described as nice people who had given him a stable home. He told us about his plans to study law after finishing school, and about saving up money to move out. Jonas's positive attitude towards his life situation and future might be unexpected to some, in light of his experiences. For Jonas, however, it was not:

I have always been loved and cared for. The neglect that I have experienced was related to Maria not being able to stop drinking ... but there was always love and care, so the neglect has never impacted on me personally in the way that might be common for other foster children.

It is within this understanding of neglect, where he distanced himself from the image of the neglected child, that he constructed his relationship with Maria. He visited her often and still saw her as his mother - a mother who dealt with difficult issues in her childhood. At the same time, he did not believe that she would be able to quit drinking, but his relationship with her was still valuable:

She has dealt with some difficult issues growing up. I don't see it as her fault that she drinks, and I don't blame her and say: 'You're an alcoholic - it's your fault - it's your choice'. I have made my peace with it. I think she should live her life the way she wants to. I don't think she is going to change. Even though she's drunk sometimes when I visit her, we have valuable moments together.

While Maria had a central position in the second interview, Anna, his birth mother, was given little space. When asked about their relationship nowadays, Jonas told the interviewer that he had had some contact with Anna after he moved into a second foster home. But, at the time of the interview, he had not spoken to her in 2 years:

I feel like I've done a lot to stay in touch, but I haven't really had a response, so ...If she wants [to have contact], it's her turn to initiate it. 
It is important to add that Jonas did not talk about his lack of contact with Anna as a problem or an on-going issue in his life. Rather, he talked about it as a matter of fact. Similar to his relationship with Maria, he did not show any anger or bitterness towards her. However, what set his relationship to Anna apart is that this relationship was up for negotiation - one that was dependent on future actions.

When we interviewed Jonas for the third time, his relationship with Anna had changed and he had had regular contact with her. Jonas was now 28 years old and worked as a lawyer. Jonas was interviewed in his flat, which he rented with friends in one of the larger cities in Norway. In what Jonas portrayed as a hectic, but happy life, his family relationships were portrayed as being both meaningful in his life today and influential in who he had become. His accounts of Maria were quite similar to what they were at $\mathrm{T} 2$, and he portrayed a close and positive parent relationship, despite Maria's continued alcohol abuse. However, while he primarily portrayed Maria as his parent at T1 and T2, he now included Anna as being one of his parents - one of his two mothers:

Maria is my mother because she has been there for me my whole life. She raised me. Anna is my mother because she gave birth to me and because she is here now. So, they are both my mothers.

According to Jonas, they had both 'given' him different things which had resulted in him being the person he had become:

I look at it as a backpack filled with different things from different people. Maria has given me so much love it's enough to drown in, and Anna gave me life ...

Looking back on the years where he did not have contact with Anna, Jonas says he did not really know why - 'it's just a part of her personality'.

Half way through the interview, after giving predominantly positive accounts of his family life and relationships, Jonas was asked more directly about why he was so generous towards his two mothers whom he could have portrayed in a very different light. At one point, Jonas said it was because he had been lucky: they had given him so much and they were important to him. At the end of the interview, Jonas added to his reasoning:

Because I'm on top of this. I know who I am, and I know who they are in my life - we are clear about what roles they have in my life and vice versa. 


\section{Maja}

At her first interview Maja was 11 years old, living in foster care with her paternal grandparents and her little brother, Eric (8). She had lived with them since she was 4 years old, from the time her birth parents were deprived of the right to care for them due to their drug abuse. Unlike Jonas, Maja had regular contact with her birth mother, Paula. This contact consisted mainly of supervised one-day visits, once every month. Her birth father, on the other hand, had died of an overdose when she was 6 years old.

The interviews with Maja's birth mother, Paula, and Maja's grandparents, Bente and Olav (conducted separately), reveal high levels of conflict between the two parties. Whereas Paula wanted to be more included in the children's lives, Bente and Olav felt it necessary to set strict boundaries for her visits because of her drug addiction. In the interview with the 10-year-old Maja, this conflict was not a topic. She said she knew why she couldn't live with her mother, but talked about the time spent with Paula with enthusiasm and pride. At the time of the second interview, Maja was 20 years old and had lived by herself since the age of 16 . Her accounts about the past - from the time she moved away from her grandparents to last year - were constructed as a phase of teenage rebellion. According to Maja, she moved out at the age of 16 because she was tired of fighting with her grandparents when they didn't allow her to do the things she wanted to do. This included visiting her mother when she wanted. Maja told us that after moving she had dropped out of school and started drinking heavily and experimenting with drugs. At the time of the interview, one of Maja's main projects was to get back on her feet. She was working in a cafe', and planned to finish her primary education. When asked why she started experimenting with drugs, Maja said:

I guess I hung out with the wrong friends or something ... and I was curious, I wanted to try but I'm glad I stopped, nothing good came of it anyway. It would have been sad to go down the same path as my mum ...

During the interview, she revealed that she had also used drugs together with her mother, but did not blame her for this. In addition, although she was clear about not wanting to end up like her mum, she gave no indication of distancing herself from her. Her grandmother had warned her about spending too much time with her birth mother. To Maja, however, her mother's situation and her own were different and could not be compared. Her mother was the one with a serious problem; she on the other hand had only tried drugs. To Maja, therefore, it was natural to visit her mother who was currently serving a prison sentence and was expected to be released 
soon. This had been Paula's longest period without drugs in a long time, and Maja was optimistic about her mother's future: 'It looks like she might be fine when she gets out ... . She's got her own flat too'.

In the third interview, Maja told us that Paula did not manage to stay off drugs for long, and neither did she. This time she had not just 'experimented', but started using heavier substances regularly. Around the age of 22, she had participated in a rehabilitation program where she met a man called Tom and became pregnant. Maja and Tom lived together for a few months after their daughter was born, before he moved out. Maja took on the primary responsibility for the baby, but Tom continued to be a part of the baby's life. According to Maja, she had been able to stay off drugs throughout the pregnancy and during the three following years. When she started using drugs again, her life situation changed. CPS became involved and it was decided that her daughter would live full-time with the child's father. After losing custody of her daughter, Maja re-entered rehabilitation.

At the time of the third interview, Maja was 28 years old. According to Maja, she had not 'touched drugs' for almost a year. She lived in a flat with her new boyfriend who also had a history of drug abuse, but had been clean for 3 years. Similar to what she said at T2, her project was to get back on her feet. This time, however, her wish was not just to get a stable job; rather, she wanted to prove that she could regain full-time custody of her daughter. She told us that her grandparents had helped her in different ways to stay off drugs and offered much support after she had lost custody of her daughter.

According to Maja, having a child had changed her relationship with her mother. First, because she did not want her daughter to see her grandmother on drugs as she had so many times. Secondly, because her mother's visits posed a threat to her own sobriety. Looking back on her mother's last visit one month earlier, Maja said:

When my mum was here last month, I noticed that she was really craving a shot... . Both me and my boyfriend noticed it... . And that sort of made us crave it too.

According to Maja, her only solution was to give her mother an ultimatum: if she wanted to be a grandmother and be a part of her life, she would have to get clean. While this can be understood as a way of distancing herself from her mother who posed a threat to herself staying sober, she was not sure how strict she would be able to be: 
The last time I spoke to her, I said: 'it's the last time, I won't give you any more chances'. But there is never a final, like ... it's more like 'it's your last chance' every time.

Maja referred here to previous experiences, the numerous times she had given her mother an ultimatum, but always given her new chances. In light of what was at stake, the interviewer asked Maja directly about how she was able to have contact with her mother who did drugs with her as a teenager, why she put up with it instead of ending their relationship. Maja nodded and smiled, indicating she understood the directness of the question:

I don't know. There is something about that mum-thing I guess... like, the closest family member you'll ever have ... . I don't know ... . Plus, we don't have the typical mother-daughter relationship. It's more like a friendship, like ... . My god, it's been almost 20 years since I lived with her... . And when I did drugs with her it was more like two friends doing it, and I guess it's easier to forgive a friend. I don't look at her as a mum, like you probably look at your mum. She's not the one who told me to brush my teeth, go to bed and all that stuff ... . My grandma did all that stuff - she's my mum, really.

\section{Ann}

Ann was 10 years old when she and her younger brother moved into foster care with her aunt (birth mother's sister) and uncle, Grete and Tom, due to her birth parents' alcohol and drug abuse. Up to this point, Ann and her brother had lived with her birth mother, Monica. Her birth father, Rolf, had lived with them until Ann was 4 years old.

At the time of the first interview, Ann was 12 years old and she was interviewed along with her brother. Both her birth parents lived within driving distance from where she lived with her aunt and uncle. The interviews with Ann's birth mother and foster parents reveal high levels of conflict and low degrees of loyalty between them. Ann's contact with her birth parents had been restricted by CPS to one weekend each month with her birth mother (unsupervised), and supervised one-day meetings with her birth father twice a year due to previous violent behaviour. 
The main issue that occupied Ann during this interview was all the 'things' she was not allowed to do by her aunt and uncle. According to Ann, 'all children' did these things, except her.

I'm almost never allowed to do anything. I'm almost never allowed to go downtown by myself ... to colour my hair ... . I have almost no designer clothes. I'm not allowed to do anything. Everyone else is, but not me ...

The lack of control that Ann conveys is not unique for children and youth; many children have experiences of relative powerlessness in their families (James, 2011: 136). However, Ann did not convey the imbalance of power as a matter of fact as many children at her age might do, but as reasons for why she did not want to live with her aunt and uncle. It was in relation to this expressed lack of power to influence her everyday life that she talked about her birth parents:

I'm not even allowed to call my dad when I want to. He is my dad, I should be allowed to call him whenever I want to.

Ann wanted to spend more time with her birth father. When asked if she knew why she was not allowed to talk to him as often as she wanted, Ann said that she knew that he had been violent with her mother. However, according to Ann, the time she spent with him was always nice 'he lets me do much more than what they [foster parents] do'. Ann gave a list of several people she would rather live with than her foster parents. Ann included her birth father on this list, but not her birth mother. While Ann talked little about her relationship with her birth mother, she looked back on the time she lived with her as a time of freedom:

When I lived with my mum I could do what I wanted. They [foster parents] don't let me do anything, not even sleep over... . Mum used to let me be with my friends whenever I wanted to.

When we interviewed Ann (21) for the second time, she portrayed an image of her childhood much consistent with the one she portrayed as a child. However, now she didn't just talk about what she was not allowed to do by her aunt and uncle, but also about their lack of parenting skills, and their meanness towards her. According to Ann, she had tried several times to tell her caseworker about her problematic living arrangement, but they never took her seriously.

Childhood neglect is a central topic in Ann's interview at this point. Ann tells us that before she turned 18 she quit school and 'finally' ran away from her aunt and uncle, and stayed for a short 
time with other family members and friends. With financial help from CPS, she was able to rent a flat, where she still lived when we interviewed her. At this point, Ann worked part time at a bakery, and received financial support from social security. She was unsure about how long she would be able to continue to work, and questioned her ability to finish her primary education and work full time in the future. According to Ann, she struggled with what she had experienced in the past:

I want to work, but... Some struggle with childhood trauma for the rest of their lives. I sit and think about what I have experienced throughout the years, but try to forget about it.

In the interview, Ann associated negative childhood experiences with both her birth parents' actions and her years in foster care with her aunt and uncle. Although Ann said that she tried to forget about the past, it was in relation to the neglected childhood and the effect it had had on her that Ann talked about her family and other relationships. Her birth mother and father, her aunt, and her little brother were still a part of Ann's everyday life. They all still lived in the same city, she saw them regularly, and they were prominent characters in the interview. Ann described their relationships to each other, and her relationship to them in terms of different degrees of conflict. The only person she did not have a conflict with now was her uncle and her little brother. Her uncle was, according to Ann, someone she could talk to about her difficult childhood, and she had forgiven him for being a bad foster parent. This more positive relationship, however, received little space in the interview compared to the on-going difficult relationships she had with others, and especially with her birth parents:

Mum and dad sitting and talking shit about each other hasn't made it easier [for Ann's life situation]. Like, when I talk to my dad he will always talk shit about my mum and her family. Then I'll tell him that 'if you say one more word you can forget having any more contact with me'

In this 'toxic web of relationships', Ann positioned herself as the person in her family who had done best in life, despite her struggles. Unlike her birth parents and her brother who had 'gone down the same path as them', she had stayed away from drugs and alcohol. When asked who she counted as important people in her life, Ann replied that she wasn't sure:

I don't know. Maybe my brother. But I can manage on my own ...I guess it's because of everything that I've been through. I'm used to taking care of myself. 
When we interviewed Ann for the third time, at the age of 29, it seemed as if little had changed in her life. Apart from getting a new boyfriend, she lived in the same city; she worked 1 day a week and received financial support from social security. The conflicts in and with her family were still a major issue and the difficult childhood - how it had been, and how it continued to be affecting her life - was a central backdrop for the interview.

According to Ann, her childhood experience was still making it difficult for her to work, and to have a good and trusting relationship with her boyfriend. However, while forgetting about the past was her strategy at T2, she had two new strategies to cope with the neglected childhood at T3. The first was to go into therapy, and the second was what Ann refers to as 'cutting ties here and there'. This involved breaking off contact with her uncle. She also restricted contact with her birth mother to a minimum. While Ann's attitude towards her birth mother at T2 can be described as unclarified or ambivalent, her accounts of her birth mother at T3 were entirely negative. According to Ann, she would care little if she died. She associated her negative feelings towards her birth mother to all the things she had done, or not done, which in turn had a negative effect on Ann's life. Her birth father, on the other hand, was now included as one of the most important people in her life, beside her boyfriend. Although he had also hurt and disappointed her throughout the years, she had managed to forgive him - something she was not able to do with her mother. The difference between the two, according to Ann, was that her birth father in different ways confirmed that she was important to him. Ann used her last birthday as an example to show the difference between her parents:

She [birth mother] didn't even call me on my birthday. The last time I saw her I said 'Are you aware that it was your daughter's birthday the other day?', and she was like 'Oh my god, I forgot', and she came up with different excuses and stuff and I thought to myself 'yeah, go ahead make excuses', I mean, a mother who brings a child into this world and cannot even remember her birthday. But my dad remembered, and he started telling the same story as he always does, like about what time I was born and that he remembers holding me in his arms and ... . It's the same story every year, so that's nice. It's more than my mum does anyway.

Ann gave various examples like this, where she would start by telling a story about her failing mother, and end with an example that portrayed her birth father in a positive light. While these examples also included accounts of Ann trying to distance herself from her mother, she had not succeeded in doing so: 
We only talk like, once a month. It would be easy to stop talking to her. I have enough problems to deal with, I don't need to listen to her complaining about her life ... but like, last week she got sick and my aunt called and told me to come to the hospital and I was like: 'Oh no! [ironic tone]. Like, I don't care', but me and my boyfriend went [to the hospital], and he was like: 'she seemed fine', and I was like: 'yeah, that's typical - my mother, the drama queen'. Had I known, I wouldn't have bothered coming.

\section{Discussion}

In this paper, we have explored Jonas, Maja and Ann's relationships with their birth parents through the ways in which they were expressed in their three interviews as children, emerging adults and young adults. The aim was to gain knowledge about the meaning and content which they themselves ascribed to such relationships and how this changed over time.

In his first interview, Jonas made sense of his relationship with his birth mother in a context where his foster mother appeared to him as his parent and his family. As we saw in the analysis, Jonas reduced the content of his relationship with his birth mother to a biological relative - an aunt - rather than a close parent-child relationship. In the second interview, Jonas's relationship to his birth mother can be understood to signify the 'conditioned relationship', meaning that the content of the relationship will depend on his birth mother's future actions. In sharp contrast, he portrayed his birth mother as his parent in the third interview, recognising her as one of his two mothers.

While Jonas's accounts of his relationship with his birth mother moved towards a parent-child relationship in adulthood, a different set of changes emerged in Maja's case. Unlike Jonas, Maja grew up in a context where her birth mother was recognised by her grandparents and by herself as her mother, and she had regular contact with her throughout her upbringing. In the first and the second interview, she more or less romanticised her birth mother, and Maja's accounts of her built on the hope that her birth mother 1 day would be able to end her drug addiction. In the third interview, Maja's birth mother was portrayed as a risk in her life. Maja, who was trying to stay away from drugs to regain custody of her child, found it necessary to demarcate distance towards her birth mother, at least for a while. Yet, she did not blame her birth mother for her previous actions, nor did she have a plan to exclude her birth mother from her life. Rather, Maja renegotiated her birth mother's role in her life from a mother to a friend. This way she could 
both forgive her birth mother for her previous actions, and continue to have her in her life, albeit with some restrictions.

Unlike Maja and Jonas, Ann had both her birth father and mother in her life. Her birth father, whom she only met on rare occasions while growing up, was someone Ann greatly missed in the first interview. In the second interview, her birth father was a part of her life, but was portrayed as one of many family members who was making Anns life difficult for her. In the third interview, this changed again as she included him as one of the most important people in her life, one who lived up to some aspects of what a parent should be. While Ann had little contact with her birth father during her childhood, she had regular contact with her birth mother. Unlike her birth father, her accounts about her birth mother reflected a more negative or ambivalent attitude. In the third interview, however, this had changed as Ann explicitly portrayed her birth mother as a burden in her life, and her relationship with her as difficult. In contrast to her birth father, her birth mother did not give her anything - she only took.

While the three cases are different in numerous ways, they all show that relationships with birth parents change over time. Yet, unlike Jonas and Maja, Ann never renegotiated the content of her relationships with her birth mother and father to signify something other than parent-child relationships. As we saw in Ann's second interview, she portrayed struggling and difficult relationships with both of her birth parents due to their lack of parenting skills. In the third interview, she portrayed a birth father who lived up to some aspects of what a parent should be, while her birth mother did not. Ann's continuing ambivalent and negative accounts of her birth mother reflect previous qualitative research where children who grew up in foster care arrangements expressed disappointment and anger towards their birth mothers regarding the quality of contact (e.g. Messing, 2006). While it is obvious from Ann's two interviews in adulthood that she did not expect her birth mother to engage in a type of 'intensive mothering', she continuously evaluated her birth mother according to such idealised versions of motherhood. As such, she would most likely continue to be angry and disappointed.

This brings us to the issue of agency. What is different between Ann and the children in Messing's study is that in her adult life, Ann (in theory) had the opportunity to choose her relationships, and more power to define what this should be and entail. Yet, while Ann's accounts reflect a wish to distance herself from her birth mother, she was not able to - it was a difficult relationship from which she couldn't escape. Throughout her accounts constructed in her adult life, Ann positioned herself as a powerless person with little control and few choices. 
This is not just visible in her accounts about her birth mother, but also in accounts of her life and future more generally.

In sharp contrast, Jonas positioned himself as a rational and resourceful individual with choices, someone who was in control of his life. To Jonas, the problems of both his foster (social) mother and his biological mother are their problems, not his. He also managed to find acceptable reasons for why things turned out the way they did in ways that did not harm him. In doing so, Jonas was also able to distance himself from the position of the neglected child, and take on an identity of someone who was in control of their relationships and their present and future life. Similarly, Maja sought to portray herself as a resourceful and rational individual who could make better choices than her birth mother - someone who was in control of her life and relationships. In contrast to Jonas, her control emerged as ad-hoc solutions. The aim of temporarily distancing herself from her birth mother to stay drug free and to regain custody of her daughter was an example of that.

While different types of agency were reflected throughout the interviewees' accounts, taking control did not involve walking away from their relationships with their birth parents in any of the cases, despite there being very good reasons to do so, given their birth parents' actions. While our sample only consists of three case studies, our findings contribute to research that challenge the individualisation thesis: not only can more or less challenging or difficult relationships be viewed as meaningful and important in one's life, but one might simply not be able to escape them. The principal question, then, is: 'What consequences would it have for Jonas, Maja and Ann if their birth parents in different ways continued to have a powerful copresence (Holland and Crowley, 2013) in their lives?' While this question is outside the scope of this paper, it is reasonable to argue that the consequences would be different in each case. To Maja, it might mean that she would never be able to stop her drug addiction; to Ann it could prevent her from constructing a life story that brought emotional satisfaction; while for Jonas it could give a sense of normality and continuity in his life.

This study, then, was a qualitative longitudinal study of relationships with birth parents deprived of parental responsibility. We have seen how such relationships can be understood and how this can change over time. The knowledge that family life and relationships are not static, but change over time has been recognised within the sociology of family life for some time. However, because qualitative longitudinal studies are still rare in most areas of research, 
we find few empirical contributions that explore how family relationships 'ebb and flow as people grow or as circumstances and context change' (Smart, 2007: 133).

As we have shown, the interviewees ascribed meaning and content to their relationships with their birth parents in relation to their life situations, their birth parents' life situations and other relationships, in relation to their interpretations of the past, the present and the future, and in relation to contemporary understandings of what a parent is or should be. They did so both in childhood and adulthood. Moreover, our study also contributes knowledge of parent-child relationships rarely focused on in family studies. Showing that such relationships can be ascribed different content and meaning, it exemplifies how parent-child relationships are not 'one thing'. To gain more insight into what such relationships can entail, research would benefit from exploring this diversity further.

Finally, while our study contributes to exemplifying diversity in parent-child relationships and showing how such relationships can change, it also shows that the interviewees' agency remained more or less consistent in both interviews in adulthood. The knowledge that children - in childhood and when they become adults - have different resources available is a reflection and a reminder of the diversity of children we find within categories such as foster care and kinship care. Neither the biological principle, nor a child-centric view such as 'attachmentsupportive development', manages to capture this variation, nor the complexities involved.

\section{Notes}

1. In the Nordic, as well as in some other European countries, long-term foster care (rather than adoption) is the preferred option when children cannot live with their birth parents. In Norway, 11,771 children were living in foster care in December 2016 (Statistics Norway, 2017). Of these, 2893 lived with non-parental relatives within child protection jurisdiction, often referred to as kinship foster care.

2. In Norway and countries such as the UK, contact is rarely terminated (Haugli and Havik, 2010; Sen and Broadhurst, 2011).

3. 'Emerging adults' and 'young adults' are based on Arnett's conceptualisation of age groups (Arnett, 2004). 


\section{References}

Achenbach TM (1991) Manual for the Child Behavior Checklist/4-18 and 1991 Profile. Burlington: Department of Psychiatry, University of Vermont.

Achenbach TM, Krokowski RA, Dumensi L, et al. (2005) Assessment of adult psychopathology: Meta-analysis and implications of cross-informant correlations. Psychological Bulletin 131: 361-382.

Aldgate J and McIntosh M (2006) Looking After the Family: A Study of Children Looked After in Kinship Care in Scotland. Edinburgh: Social Work Inspection Agency.

Arnett JJ (2004) Emerging Adulthood: The Winding Road from the Late Teens through the Twenties. New York: Oxford University Press.

Beck U and Beck-Gernsheim E (1995) The Normal Chaos of Love. Cambridge, UK: Polity Press.

Bowlby J (1969) Attachment and Loss: Volume 1: Attachment. New York, NY: Basic Books.

Bullen T, Taplin S, Kertesz M, et al. (2015) Literature Review on Supervised Contact between Children in Out-of-Home Care and Their Parents. Canberra: Institute of Child Protection Studies, ACU.

Elder G (1991) Lives and social change. In: Heinz W (ed.) Theoretical Advances in Life Course Research. Weinham, Germany: Deutscher Studies Verlag, pp.58-114.

Elliot J, Holland J and Thomson R (2008) Longitudinal and panel studies. In: Alasuutar P, Bickman L and Brannen J (eds) Handbook of Social Research Methods. London, UK: Sage, pp.447-460.

Eronen T (2011) Three stories about mother: Narratives by women who have lived in care. Child and Family Social Work 17: 66-74.

Fahlberg VI (1991) A developmental approach to separation/loss. In: Hibbs ED (ed.) Adoption: International Perspectives. Madison, CT: International Universities Press, pp.27-33.

Faircloth C (2014) Intensive Fatherhood? The (Un)involved Dad. In: Lee E, Bristow J, Faircloth C, et al. (eds) Parenting Culture Studies. New York, NY: Palgrave Macmillan, pp.184-199.

Farmer E and Moyers S (2008) Kinship Care: Fostering Effective Family and Friends Placements. London, UK: Jessica Kingsley.

Finch J and Mason J (1993) Negotiating Family Responsibilities. London, UK: Routledge.

Giddens A (1979) Central Problems in Social Theory. London, UK: Palgrave Macmillan.

Giddens A (1992) The Transformation of Intimacy: Sexuality, Love and Eroticism in Modern Societies. Cambridge, UK: Polity Press. 
Gillis JR (1996) A World of Their Own Making. Cambridge, MA: Harvard University Press.

Haugli T and Havik T (2010) Samvær i barnevernsaker. Psykologiske og juridiske vurderinger. Oslo, Norway: Universitetsforlaget.

Hays S (1996) The Cultural Contradictions of Motherhood. New Haven, CT: Yale University Press.

Holland S and Crowley A (2013) Looked-after children and their birth families: Using sociology to explore changing relationships, hidden histories and nomadic childhoods. Child \& Family Social Work 18: 57-66.

Holtan A (2002) Barndom i fosterhjem i egen slekt. Doctoral dissertation, University of Troms $\varnothing$, Norway.

Holtan A (2008) Family types and social integration in kinship foster care. Children and Youth Services Review 30: 1022-1036.

Holtan A and Eriksen S (2006) The brittle attraction: Women deprived of the custody of children. International Journal of Child and Family Welfare 9: 178.

Holtan A, Handegard BH, Thørnblad R, et al. (2013) Placement disruption in long-term kinship and nonkinship foster care. Children and Youth Services Review 35: 1087-1094.

James A (2011) 'The things children say': Understanding children as narrators of their lives. In: Jamieson L, Simpson R and Lewis R (eds) Researching Families and Relationships. Basingstoke: Palgrave Macmillan, pp. 135-138.

Kiraly M and Humphreys C (2013a) Family contact for children in kinship care: A literature review. Australian Social Work 66: 358-374.

Kiraly M and Humphreys C (2013b) Perspectives from young people about family contact in kinship care: “Don’t Push Us_Listen More.” Australian Social Work 66: 314-327.

Lee E, Bristow J, Faircloth C, et al. (2014) Parenting Culture Studies. New York, NY: Palgrave Macmillan.

Levin I (1994) Stefamilien - variasjon og mangfold Oslo, Norway: Aventure.

Maaskant AM, van Rooij FB, Bos HMW, et al. (2016) The wellbeing of foster children and their relationship with foster parents and biological parents: A child's perspective. Journal of Social Work Practice 30: 379-395.

Mallett S (2004) Understanding home: A critical review of the literature. The Sociological Review 52: 62-89.

Mallon GP and Hess M (2014) Child Welfare for the 21st Cetury. A Handbook of Practices, Policies, and Programs. New York, NY: Columbia University Press. 
Messing JT (2006) From the child's perspective: A qualitative analysis of kinship care placements. Children and Youth Services Review 28: 1415-1434.

Milham S, Bullock R, Hosie K, et al. (1986) Lost in Care: The Problems of Maintaining Links between Children in Care and Their Families. Aldershot, UK: Gower.

Morgan D (1996) Family Connections: An Introduction to Family Studies. Cambridge, UK: Polity Press.

Morgan D (2011) Rethinking Family Practices. Hampshire, UK: Palgrave Macmillan. Moxnes K (1999) From Modern to Postmodern Families. Trondheim, Norway: NTNU. 